AperTO - Archivio Istituzionale Open Access dell'Università di Torino

\title{
Stereochemical Assignment of Strigolactone Analogues Confirms Their Selective Biological Activity
}

\section{This is the author's manuscript}

Original Citation:

Availability:

This version is available http://hdl.handle.net/2318/1533499

since 2017-11-20T18:06:42Z

Published version:

DOI:10.1021/acs.jnatprod.5b00557

Terms of use:

Open Access

Anyone can freely access the full text of works made available as "Open Access". Works made available under a Creative Commons license can be used according to the terms and conditions of said license. Use of all other works requires consent of the right holder (author or publisher) if not exempted from copyright protection by the applicable law. 


\section{Stereochemical Assignment of Strigolactone}

\section{Activity}

4 Emma Artuso,${ }^{\dagger}$ Elena Ghibaudi, ${ }^{\dagger}$ Beatrice Lace ${ }^{\dagger}$ Domenica Marabello, ${ }^{\dagger}$ Daniele Vinciguerra, ${ }^{\dagger}$

5 Chiara Lombardi, ${ }^{\dagger}$ Hinanit Koltai, ${ }^{\perp}$ Yoram Kapulnik, ${ }^{\perp}$ Mara Novero, ${ }^{\ddagger}$ Ernesto G. Occhiato, ${ }^{\S}$

6 Dina Scarpi,${ }^{\S}$ Stefano Parisotto,${ }^{\dagger}$ Annamaria Deagostino,${ }^{\dagger}$ Paolo Venturello, ${ }^{\dagger}$ Einav Maylish-Gati,

$7 \stackrel{\perp}{ }$ Ariel Bier, $\stackrel{\perp}{\text { and Cristina Prandi }}{ }^{\dagger}{ }^{*}$

8 'Department of Chemistry, University of Turin, via P. Giuria 710125 Turin, Italy

9 DBIOS, University of Turin, viale Mattioli 25, 10125 Turin, Italy.

10 § Department of Chemistry “Ugo Schiff”, University of Florence, via della Lastruccia 13, 50019 Sesto Fiorentino, Italy 
1 ABSTRACT: Strigolactones (SLs) are new plant hormones with various developmental

2 functions. They are also soil signalling chemicals that are required for establishing beneficial

3 mycorrhizal plant/fungus symbiosis. In addition, SLs play an essential role in inducing seed

4 germination in root-parasitic weeds which are one of the seven most serious biological threats to

5 food security. There are around 20 natural SLs that are produced by plants in very low quantities.

6 Therefore, most of the knowledge of SLs signal transduction and associated molecular events is

7 based on the application of synthetic analogues. Stereochemistry plays a crucial role in the

8 structure-activity relationship od SLs as compounds with unnatural D-ring configuration may

9 induce biological effects that are unrelated to SLs. We have synthesized a series of strigolactone

10 analogues, whose absolute configuration has been elucidated and put in relation with their

11 biological activity, thus confirming the high specificity of the response. Analogues bearing the

12 R-configured butenolide moiety showed enhanced biological activity which highlights the

13 importance of this stereochemical motif. 
1 Strigolactones (SLs) are a new class of plant hormones whose potential in agricultural

2 applications has been fuelling intense applied and pure research, both applied and pure. ${ }^{1}$ They

3 have recently been assessed as a new class of plant hormones having effects on shoot branching ${ }^{2}$,

4 root development, ${ }^{3}$ photomorphogenesis, ${ }^{4}$ besides acting as signalling molecules in the

5 rhizosphere where they induce hyphal branching in arbuscular mycorrhizal fungi (AMF) ${ }^{5}$ and

6 seed germination in parasitic plants. ${ }^{6}$ Natural SLs all share the same basic framework which

7 consists of a tricyclic $\mathrm{ABC}$ nucleus connected with a butenolide moiety (D-ring) by means of an

8 enol ether bridge (Figure 1). ${ }^{1 \mathrm{~b}}$ They can therefore, be classified as Michael acceptors. More than

920 natural SLs have been identified ${ }^{1 \mathrm{a}, 7}$ while it is likely that others will be found in the near

10 future. This leads to questions as to why plants produce blends of SLs and whether quantitative

11 and qualitative differences in SL production and/or exudation are important in host recognition. ${ }^{8}$

12 More recently still, SLs and analogues have even been shown to act as promising anticancer

13 agents. ${ }^{9,10}$ Strigolactones are very active molecules and indeed occur in very low abundances in

14 root exudates, which is why assessments of their biological activity and unambiguous

15 configurational assignments are often hampered. ${ }^{\text {la }}$ The structural characterization of natural SLs

16 and extensive structure-activity studies (SAR) have revealed that the bioactiphore resides in the

17 CD-ring (Figure 1) portion of the molecule. This has enabled the design and synthesis of SL

18 analogues that show much simpler structures than natural SLs but still retain their bioactivity. ${ }^{11}$

19 Most natural SLs show ( $\left.2^{\prime} \mathrm{R}\right)$ absolute configuration while the correct configuration of (-)-

20 orobanchol $(\mathbf{3})$ has recently been unequivocally confirmed. ${ }^{12}$ It is now generally accepted that

21 SLs can be stereochemically grouped into two families (Chart 1), one in which the configuration

22 of the BCD-ring system is the same as (+)-strigol (1) and the other in which the configuration of

23 the BCD-ring system is the same as (-)-orobanchol (3). ${ }^{13}$ 

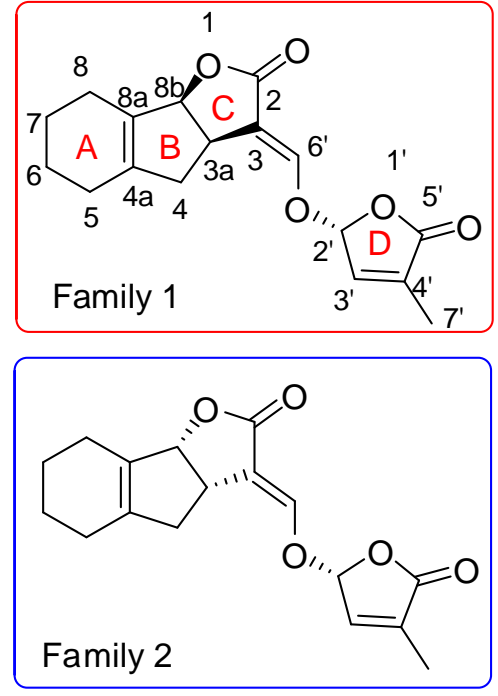

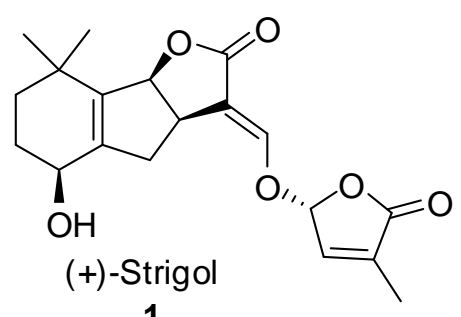

1

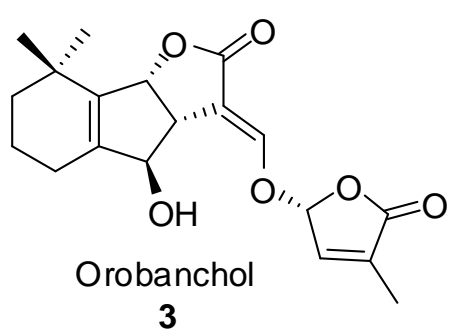

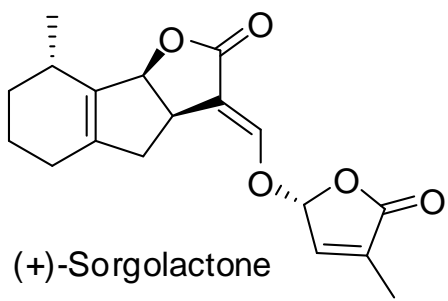

2<smiles>[R4]C([18F])[14CH2][C@H]1C=C(C)C(=O)O1</smiles>

2 Figure 1. General structures and configurations of some natural SLs and of the synthetic 3 analogue (+)-GR24

4 An analysis of mutants that are insensitive to pharmacological applications of SLs has led to the 5 identification of DAD2 in petunia as the putative receptor that is able to hydrolyze SLs. ${ }^{14}$ DAD2, 6 AtD14 (Arabidopsis thaliana), and D14 (Oryza sativa) have been assessed by X-ray analysis 7 and found to belong to the $\alpha, \beta$-hydrolases family. ${ }^{15}$ In $A$. thaliana, $\alpha, \beta$-hydrolases KAI2 and 8 AtD14 are responsible for responses to karrikins, ${ }^{16}$ chemical compounds found in plant-derived 9 smoke, ${ }^{17}$ and SLs respectively. It was recently demonstrated that AtD14 and KAI2 exhibit 10 selectivity to the 2 'R or 2 'S strigolactone D-ring configurations, respectively. However, AtD14 11 mediates SLs response only while KAI2 mediates responses to KARs and to some SLs

12 analogues. ${ }^{18}$ Structure Activity Relationship studies on shoot branching inhibition in rice and 13 Arabidopsis have recently demonstrated that the $\left(2^{\prime} \mathrm{R}\right)$ configuration has significant influence on 14 hormonal activity. ${ }^{19}$ 
1 An assessment of the configurations of SLs and analogues is therefore mandatory to avoid the

2 activation of responses that are not related to SLs and therefore the misinterpretation of our

3 results. Furthermore, the use of pure stereoisomers can furnish valuable information as to the

4 structural requirements for distinct perception systems in plants, parasitic weeds, and arbuscular

5 mycorrhizal fungi.

6 Difficulties in synthesizing natural SLs, caused by the long multistep syntheses, and their low

7 availability from natural sources have prompted chemists to develop synthetic analogues that are

8 readily accessible in sizeable quantities, stable, and whose activity may be related to that of

9 natural SLs. One added advantage of this approach is the ability to obtain more information

10 about the structural requirements for the activation of specific perception systems and the

11 specificity of the target functions. Our contribution to the field has been the development of a

12 family of indolyl derived analogues named EGOs. ${ }^{20}$

13 The synthetic procedure is feasible as it starts from inexpensive reagents and multigram

14 preparations are readily accomplished. The analogues were designed with the specific aim of

15 reducing stereochemical complexity, and the only stereocenter retained is the C-2' position.

16 Compounds that are obtained as racemic mixtures are readily separated by chiral semipreparative

17 HPLC (Figure 1S, Supporting Information). Several biological assays have been carried out on

18 various target systems using EGO analogues ${ }^{21}$ in the past and some new ones are herein

19 presented. However, the elucidation of the absolute configuration of pure enantiomers, is

20 described here for the first time.

21 In this paper we report the assignment of the absolute stereochemistry of parent EGO10

22 compounds (5, 6 Figure 2) by X-ray analysis and electronic circular dichroism (ECD), and the 
1 configurations of the other members of the family, by comparing ECD data is described. Once

2 the absolute configurations of the pure enantiomers are established, we then correlate some past,

3 and other unpublished results with the biological effects induced by the EGO analogues, thus

4 shedding light on the importance of configuration in SLs response. An EGO10 derivative

5 (MEB55), which is active as an anticancer agent, and some fluorescent tagged analogues

6 (EGOBP and BPGR24), which are used for bio-imaging applications, are included among the

7 analogues taken into consideration..

8 RESULTS AND DISCUSSION

9 Chemistry. Our interest in developing new synthetic SL analogues has manifested in two

10 principle aims: a) to extend the structure-activity relationship in varying systems for each of the

11 different roles ascribed to SLs, and b) to develop active fluorescent SL analogues that are

12 suitable for bioimaging studies and in vivo detection to map strigolactones distribution in plants

13 and fungi. We have recently reported the synthesis of a new class of Strigolactone analogues that

14 show interesting luminescent properties. ${ }^{22}$ We have also developed a new class of indolyl

15 derived compounds named EGO which can be functionalized with different substituents on the A

16 ring. ${ }^{21 b, 23}$ Furthermore in view of the use of SL analogues as fluorescent probes in the in vivo

17 mapping of the dynamic processes in which SLs are involved, we have designed a new

18 generation of fluorescent analogues whose properties are suitable for confocal microscopy

19 investigations using the well-known fluorescent BODIPY based probes. ${ }^{24}$ 


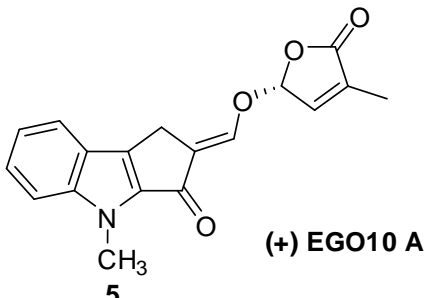

5

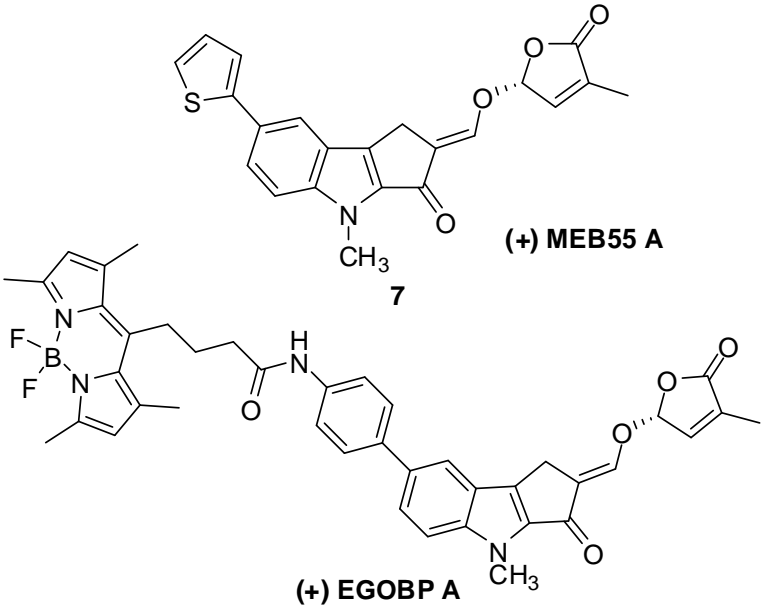

9
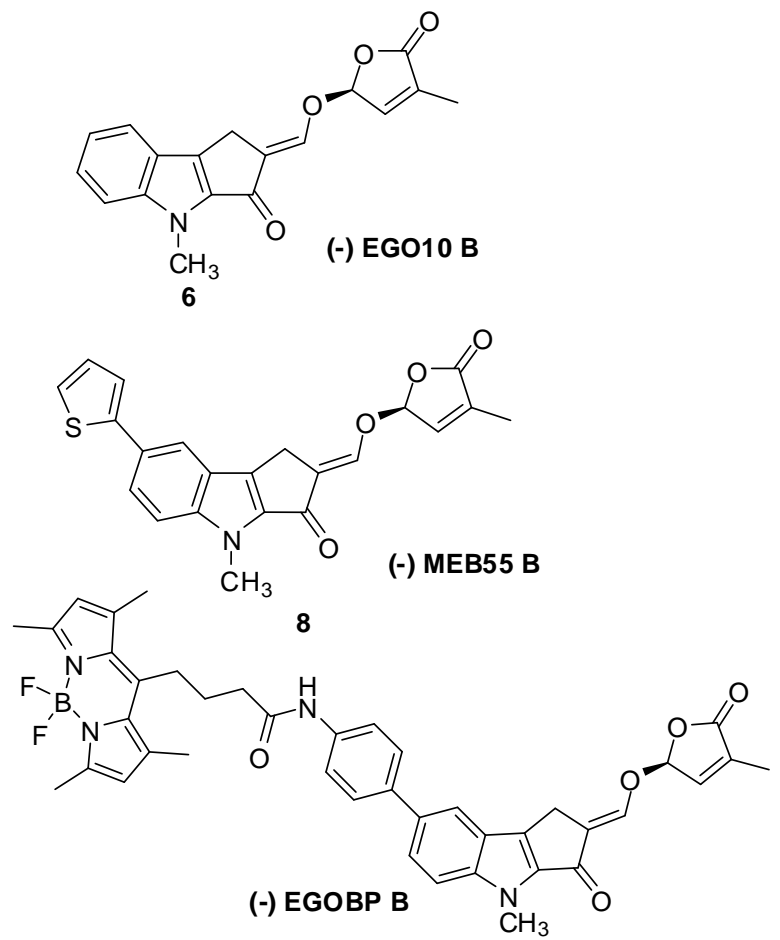

10

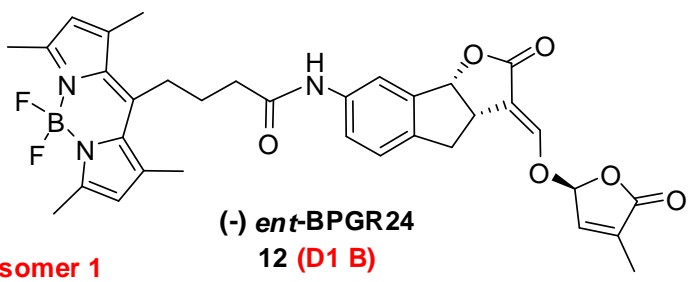

(+) BPGR 24

11 (D1 A)

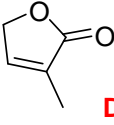

Diastereoisomer 1

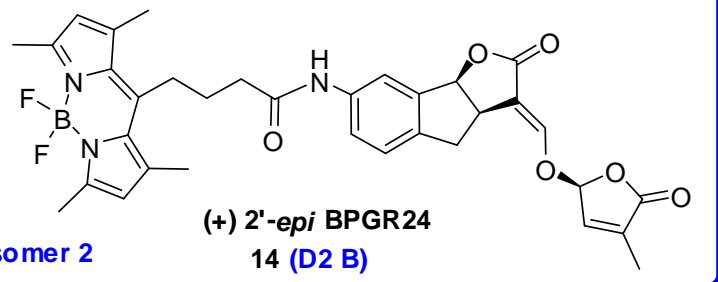

3 Figure 2. Series of SL analogues as pure enantiomers

4 EGO10 $(5,6)$ and MEB55 $(\mathbf{7}, \mathbf{8})$ were synthesized as previously described. ${ }^{21 b, 23}$ EGOBP A (9)

5 and EGOBP B (10) were synthesized and used for in vivo visualization. ${ }^{22}$ In addition, SL

6 analogue GR24 (4) was used as the core structure due to its widespread use as a standard for 
1 biological assays. The fluorophore BODIPY can be linked to GR24. To this purpose amino-

2 GR24 (19, Scheme 1) was synthesized from nitro- derivative 15, but with a slight modification to

3 the reported procedure. ${ }^{25}$ Compound $\mathbf{1 8}$ was obtained as a mixture of stereoisomers, more

4 specifically as two racemic diastereomers which were separated by column chromatography.

5 From this point onwards, the reactions were carried out on the separate diastereomers.

6 Scheme 1. Synthetic procedure to BPGR24 as a mixture of stereoisomers ${ }^{\mathrm{a}}$<smiles>CC#CC(C)C(C)(C)C(=O)Nc1ccc2c(c1)C1OC(=O)CC1C2</smiles><smiles>CC1=CC(O/C=C2\C(=O)OC3CC2C(C=C2OC(O/C=C4\C(=O)OC5c6cc(NC(=O)OC(C)(C)C)ccc6CC45)C=C2C)Cc2ccc(N)cc23)OC1=O</smiles>

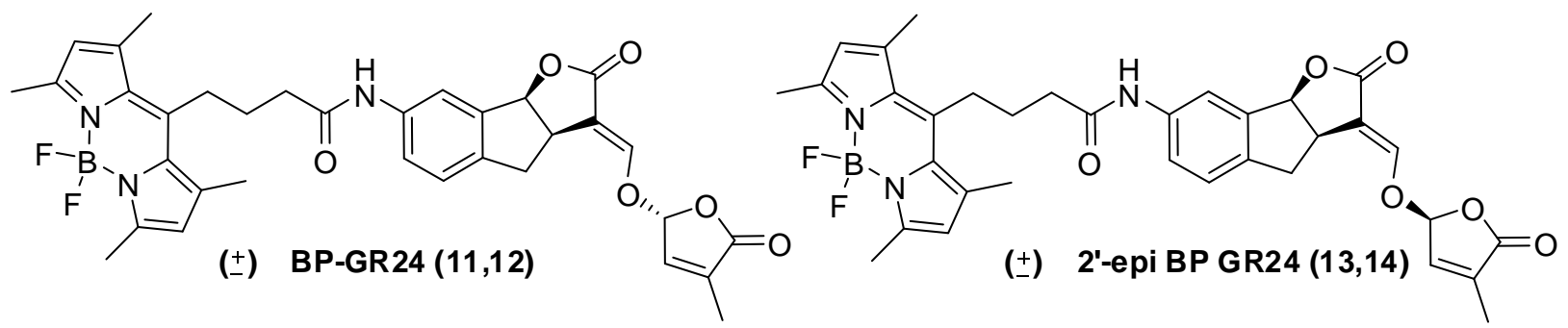

$9{ }^{\mathrm{a}}$ Reagents and conditions: (i) $\mathrm{Zn} / \mathrm{CaCl}_{2}$, EtOH- $\mathrm{H}_{2} \mathrm{O}$, reflux, $2 \mathrm{hs}\left(80 \%\right.$ ); (ii) $t-\mathrm{Boc}_{2} \mathrm{O}$, DMAP, THF, 10 reflux, $18 \mathrm{~h}(80 \%)$; (iii) $\mathrm{HCOOEt}, t$-Boc $2 \mathrm{O}$, DME, rt, $2 \mathrm{~h}$ then 5-bromo-3-methylfuran-2(5H)-one, rt,.18 11 hs (62\%); (iv) TFA, DCM, rt, 2h (93\%); (v), CDMT, NMM, DCM, rt, 18 h (78\%). 
1 After the introduction of the D-ring, compound $\mathbf{1 8}$ was deprotected and coupled with the

2 corresponding BODIPY fragment $\mathbf{2 0}$ according to the Kaminski procedure and obtained with a

$378 \%$ yield. $^{26}$ The racemic mixtures were then separated via chiral HPLC (Figures 4 and 5 ,

4 Supporting Information) and the four stereoisomers (+) BPGR24 (11), (-) ent BPGR24 (12), (+)

5 2'-epi BP GR24 (14) and (-) ent 2'-epi BP GR24 (13) were fully characterized. The absolute

6 configurations were determined on the base of ECD data as described in the next section, and via

7 a comparison of chromatographic behavior with parent GR24 standards.

8 X-ray Analysis. Crystals of EGO10A (5) that were suitable for X-ray diffraction analysis were

9 obtained via the slow evaporation of a methanol solution. Since the molecule is only composed

10 of light atoms, $\mathrm{X}$-ray data were collected using $\mathrm{Cu}$-K $\alpha$ radiation $(\lambda=1.5418 \AA$ ), which furnishes a

11 more accurate determination of absolute configuration even when heavy atoms are not present in

12 the molecule. The ORTEP plot of the molecule is shown in Figure 3.

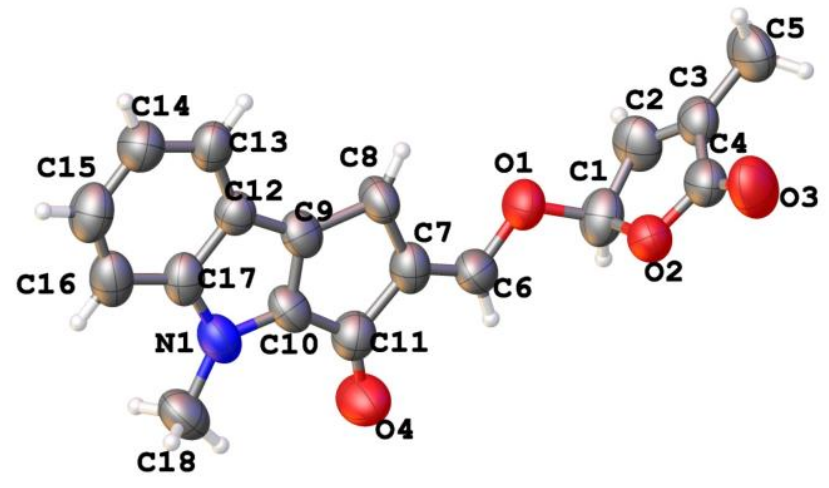

14 Figure 3. ORTEP plot of compound EGO10A (5) with atom labelling. Thermal ellipsoids of 15 non-hydrogen atoms are represented at 50\% probability.

16 Although the diffraction capability of the crystal was low, the data collected were sufficient to 17 unequivocally determine the absolute configuration, via the Parsons method. ${ }^{27}$ As shown in 
1 Figure 3 the resulting absolute configuration of compound EGO10A is $R$ at the C-1 (C-2')

2 stereocenter. $^{28}$

3 ECD Measurements. The ECD spectra of submillimolar solutions of each of the EGO10 (5, 6)

4 and $\mathrm{EGOBP}(\mathbf{9}, \mathbf{1 0})$ stereoisomer were recorded in $\mathrm{MeCN}$, in order to collect evidence for the

5 absolute configuration of the $\mathrm{C} 2$ ' stereocenter.

6

13 Figure 4 (panel A) shows the ECD spectra of enantiomers A and B of EGO10, EGOBP and 14 MEB55 in the 200-300 nm region. All these compounds contain a single C-2' stereocenter.

Figure 4 - Panel A: ECD spectra of EGO10 A (5, a) and B (a'), EGOBP A $(\mathbf{9}, b)$ and B $\left(\mathbf{1 0}, b^{\prime}\right)$,
MEB 55 A $(\mathbf{7}, \mathrm{c})$ and B $\left(\mathbf{8}, \mathrm{c}^{\prime}\right)$; Panel B: ECD spectra of BPGR24 (11, d) ent-BPGR24 $\left(\mathbf{1 2}, \mathrm{d}^{\prime}\right)$, ent-2'-epi-BPGR24 (13, e) and 2'-epi-BPGR24 (14, e'). $R$ stereoisomers at C-2' are outlined in black; $S$ stereoisomers at C-2' are outlined in dark grey. All stereoisomers were dissolved in $\mathrm{MeCN}$ at submillimolar concentration. 0 were dissolved in MeCN at submillimolar concentration.
A

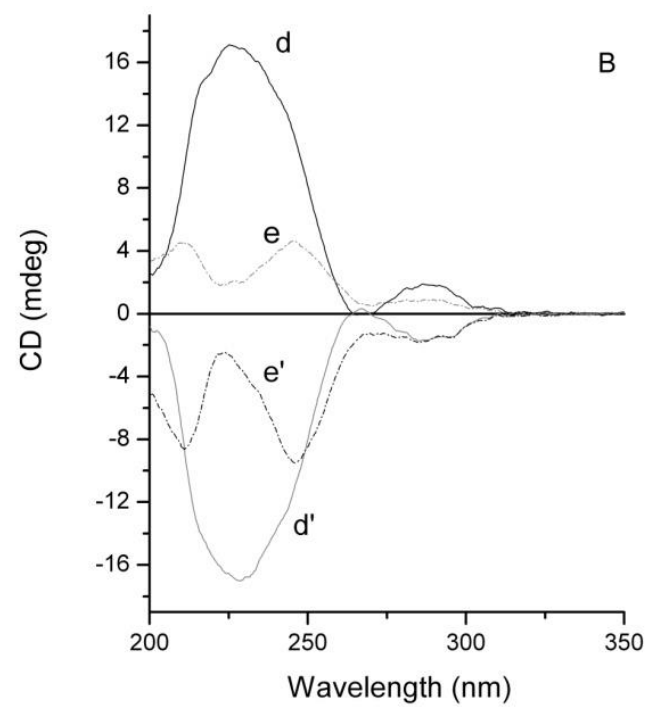

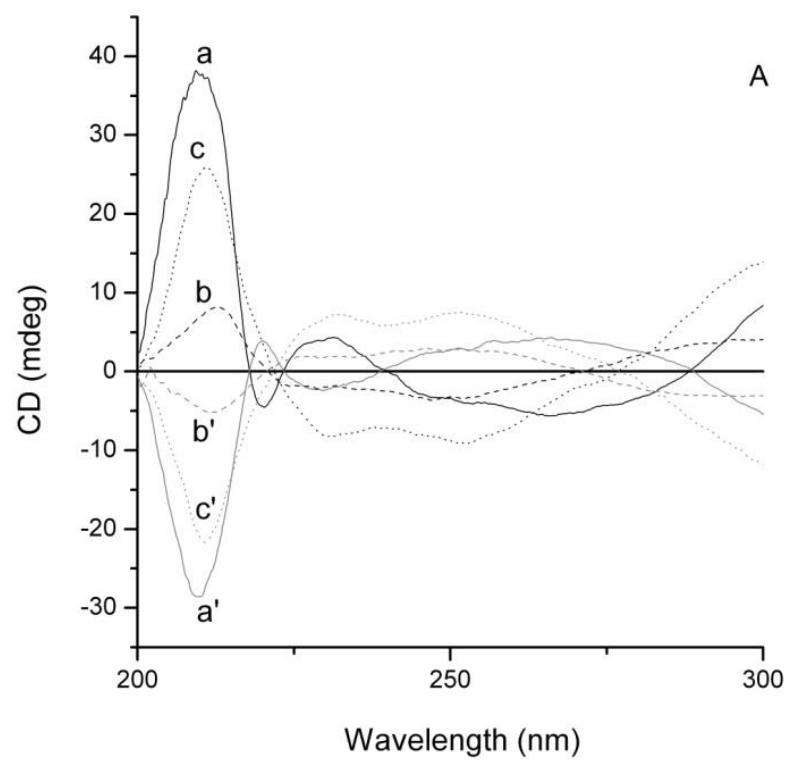


1 Labels A and B were initially assigned according to enantiomer HPLC behaviour: the A species

2 eluted before the B species in our experimental conditions (see HPLC chromatograms in Figures

3 1S-5S in Supporting Information). The spectroscopic patterns associated with the three

4 'stereoisomers A' share similar features, and the same is true for the 'stereoisomers B' set. The

5 full ECD spectra of these compounds in the 200-450 nm range are reported in the Supporting

6 Information (Figures 6S and 7S). The stereochemical assignments of SLs stereocenters by ECD

7 spectroscopy generally relies on the empirical rule proposed by Frischmuth et al..$^{29}$ According to

8 this rule, compounds that exhibit a negative Cotton effect around $270 \mathrm{~nm}$ have a $2^{\prime} R$

9 configuration, whereas a positive Cotton effect band is typical of $2^{\prime} S$ configuration. The rule is

10 grounded on two basic assumptions: i) an absence of electronic interactions between

11 chromophoric systems $\mathrm{C}$ and $\mathrm{D}$; ii) the conformational identity of $\mathrm{C}-2^{\prime}$ epimers. According to

12 these assumptions, rings $\mathrm{C}$ and $\mathrm{D}$ provide independent contributions to the $\mathrm{ECD}$ spectrum and

13 the region around $270 \mathrm{~nm}$ is mainly related to electronic transitions that involve the ring $\mathrm{D}$

14 chromophore. Despite the clearly approximate character of such assumptions, the rule has proven

15 to be effective for a number of strigolactone stereoisomers. ${ }^{30}$ As far as EGO10, EGOBP and

16 MEB55 compounds are concerned, stereoisomers A exhibit a negative Cotton effect band

17 around $270 \mathrm{~nm}$; hence, according to Frischmuth's rule, the absolute configuration of the C-2'

18 center is $R$ in all three compounds, whereas stereoisomers B possess a C-2'S absolute

19 configuration. This assignment is supported and confirmed by a number of consistent pieces of

20 evidence. In fact, the X-ray structure of EGO10 A (5) unambiguously shows a $\mathrm{C}-2^{\prime} R$

21 configuration. In addition, the three stereoisomers that belong to set A are chemically correlated,

22 in that they are obtained via a synthetic procedure that cannot perturb stereocenter $\mathrm{C}-2$. The

23 same is true for set B. Hence each set must share the same absolute configuration at C-2". 
1 Further supporting evidence is the fact that the chromatographic behavior of stereoisomers A

2 stereoisomers A vs. B towards chiral phases is homogeneous within sets. This argues in favour

3 of the same $\mathrm{C}-2^{\prime}$ absolute configuration in each set of molecules. All the evidence collected for

4 EGO10, EGOBP and MEB55 is consistent with the assignment of the $\mathrm{C}-2^{\prime} R$ configuration to set

5 A and the C-2'S to set B. Figure 4 (panel B) shows the ECD spectra of the four diastereoisomers

6 BPGR24 (11), ent-BPGR24 (12), 2'-epi-BPGR24 (14) and ent-2'-epi-GR24 (13, Figure 2). These

7 compounds exhibit peculiar ECD spectral patterns, unlike the previous sets of molecules as do

8 other known strigolactones. In particular, no sign inversion is observed for the Cotton effect in

9 the $200-350 \mathrm{~nm}$ range and the Frischmuth's rule is no longer applicable. This is probably related

10 to the disappearance of the premises upon which the rule was grounded: either conformational

11 issues influence the spectral pattern or the claimed electronic independence of ring $\mathrm{C}$ and $\mathrm{D}$ can

12 no longer be assumed. A completely unambiguous assignment of the absolute configuration in

13 the presence of conformational or electronic factors mayt require a complex approach, based on

14 the combination of ECD, VCD and theoretical calculation. ${ }^{31}$ Nevertheless, the combination of

15 several distinct experimental findings (X-ray structure, ECD data, chemical correlation, and

16 chromatographic behaviour) provides sufficient evidence for configurational assignment by

17 analogy. In fact, as these compounds are GR24 derivatives, ECD spectra may be analyzed by

18 comparison with the well-known CD patterns of GR24 and its diastereoisomers ${ }^{32}$ (see Figure 7S,

19 Supporting Information) which do not follow Frischmuth's rule either. (+) GR24 (4) has been

20 definitely shown by Scaffidi and coworkers to display a C-2'R configuration and its ECD

21 spectrum exhibits a positive Cotton effect in the 210-260 nm range. Both BPGR24 (11) and ent-

22 2'-epi-BPGR24 (12) show positive Cotton effect in the very same spectral region, which would

23 suggest an analogous $\mathrm{C}-2^{\prime} R$ configuration for both of them. The distinct features of the ECD 
1 patterns of diastereoisomers BPGR24 (11) and ent-2'-epi-BPGR24 (12) are certainly related to

2 differences in the electronic energy levels: ent-2'-epi-BPGR24 (13) exhibits three resolved

3 Cotton effect while BPGR24 (11) shows only two. However, the Cotton effect at $230 \mathrm{~nm}$ is

4 clearly not a pure Gaussian curve, which means that it is the convolution of more than one

5 contribution. Hence, the ECD spectra of BPGR24 and ent-2'-epi-BPGR24 are consistent overall.

6 Further arguments in support of the C-2'R assignment for BPGR24 and ent-2'-epi-BPGR24 are

7 the chemical correlation between these two stereoisomers and (+)-GR24 as well as analogies in

8 the chromatographic behaviour of the species. In conclusion, ECD data collected on the EGO

9 and BPGR24 series of strigolactones clearly show that EGO derivatives fulfil Frischmuth's rule,

10 whereas BPGR24 derivatives do not. Experimental evidence converges towards the assignment

11 of $R$ configurations for the C-2' stereocenter of EGO10 A (5), EGO-BP A (9), MEB55 A (7),

12 BPGR24 (11) and ent-2'-epi-BPGR24 (13).

13 Biological activity. The simplest molecules that were separated as pure enantiomers were

14 EGO10 A (5) and EGO10 B (6) whose absolute configuration corresponds to $R$ for EGO10 A

15 and $S$ for EGO10 B, as demonstrated by X-ray analysis and ECD data. 
EGO $10 \mathrm{~A}$ and B

germination activity on Peliphanche eagyptiaca

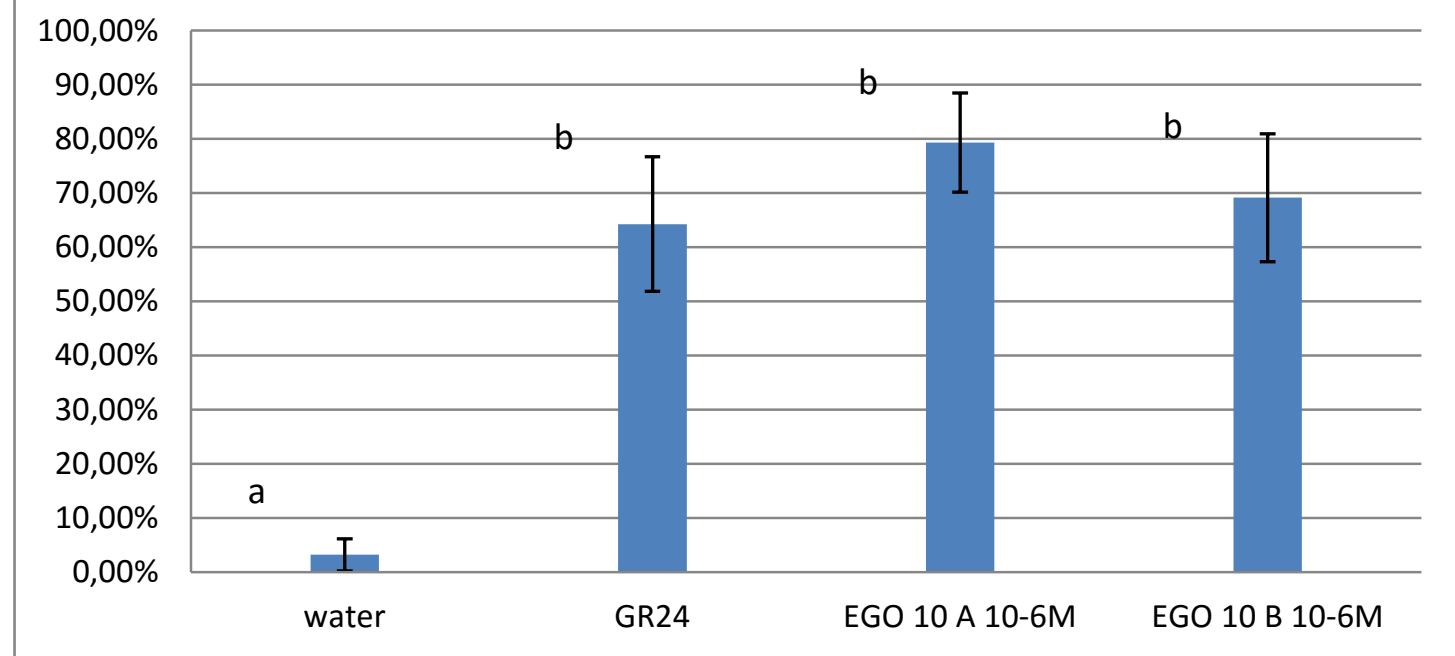

2 Figure 5. Bar graph representation of germinated seed percentages ( $\mathrm{Y}$ axis) of Phelipanche 3 aegyptiaca after exposure to pure enantiomers of EGO10 A and B.

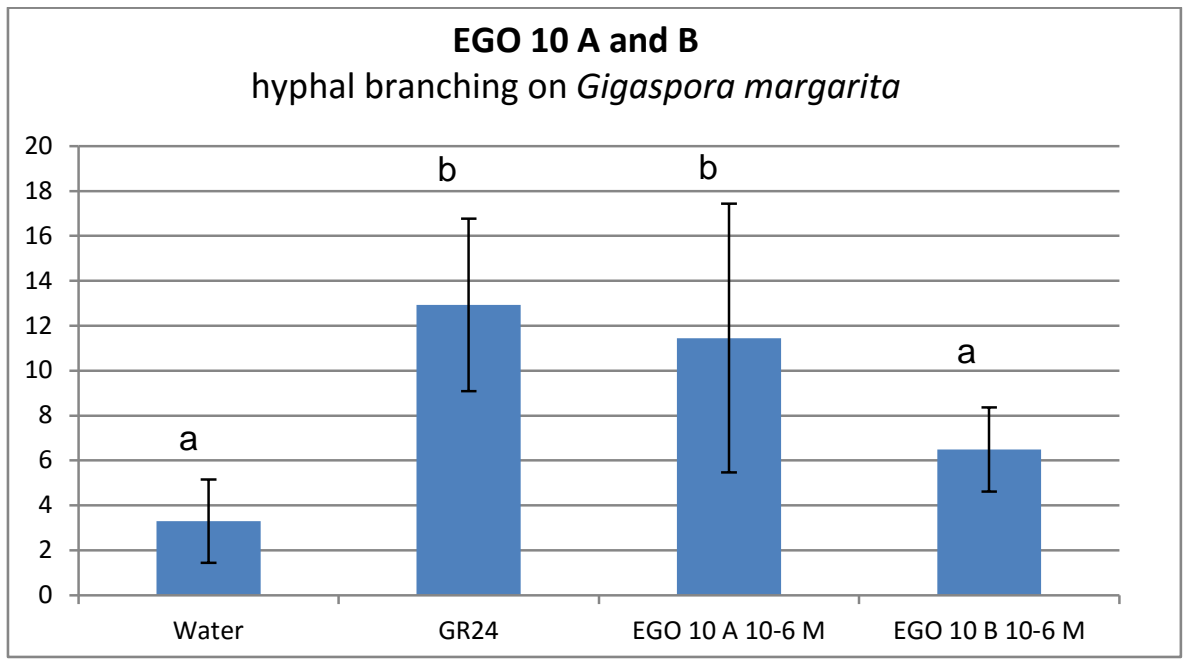

5 Figure 6. Bar graph representation of hyphal branching number per hyphal apex of Gigaspora 6 margarita after exposure to the two pure enantiomers of EGO10 A $(R)$ and EGO10 B $(S)$.

$7 \quad$ Figures 5 and 6 clearly show that enantiomers EGO10 A and EGO10 B exhibit significantly 8 different activity in the hyphal branching test, EGO10 A $(R)$ is the most active, while conversely, 
1 the activity of these enantiomers on Peliphanche aegyptiaca seeds does not show any statistical

2 difference.

3 This result is consistent with the recently reported data, according to which the non-natural

4 enantiomer of SLs can activate biological responses through perception systems unrelated to

5 SLs. $^{32}$

6 Root Hair Elongation. The hormonal activity of the enantiomers of EGO10 on root hair

7 elongation has also been evaluated on Arabidopsis thaliana, using a well-established protocol. ${ }^{33}$

8 Racemic EGO10's strong positive effect on RH elongation has already been demonstrated. ${ }^{34}$

9

10 Figure 7. Root hair length $(\mu \mathrm{m})$ in root segments of Arabidopsis thaliana after exposure to

11 EGO10 A $(R)$ and EGO10 B $(S)$, EGO10-mD at $0.1 \mu \mathrm{M}$ concentration.

12 As shown in the bar graph in Figure 7, the effect of EGO10A $(R)$ is statistically larger than that

13 of its enantiomer EGO10B $(S)$. In addition the effect of EGO10 without the D-ring (EGO10-mD)

14 was considered in order to demonstrate the role of the enol ether bridge and the D-ring in 15 inducing biological effects. In fact, EGO10-mD was as ineffective as EGO10 B. 
1 MEB55. Thiophene derivatives were synthesized according to known procedure and separated

2 into pure enantiomers (see Figure $2 \mathrm{~S}$, Suppporting Information). The activity of racemic

3 mixtures of MEB55 had already been tested on Peliphanche aegyptiaca seeds and good activity

4 was reported. ${ }^{23}$

5 We next measured the activity of enantiomers at the same concentration at which the racemic

6 mixture proved to be most active. As shown in Figure 8 the two enantiomers behave differently,

7 MEB55 A $\left(7,2^{\prime} R\right)$ is much more active than both MEB55 B $\left(8,2^{\prime} S\right)$ and racemic GR24 which

$8 \quad$ was used as a standard.

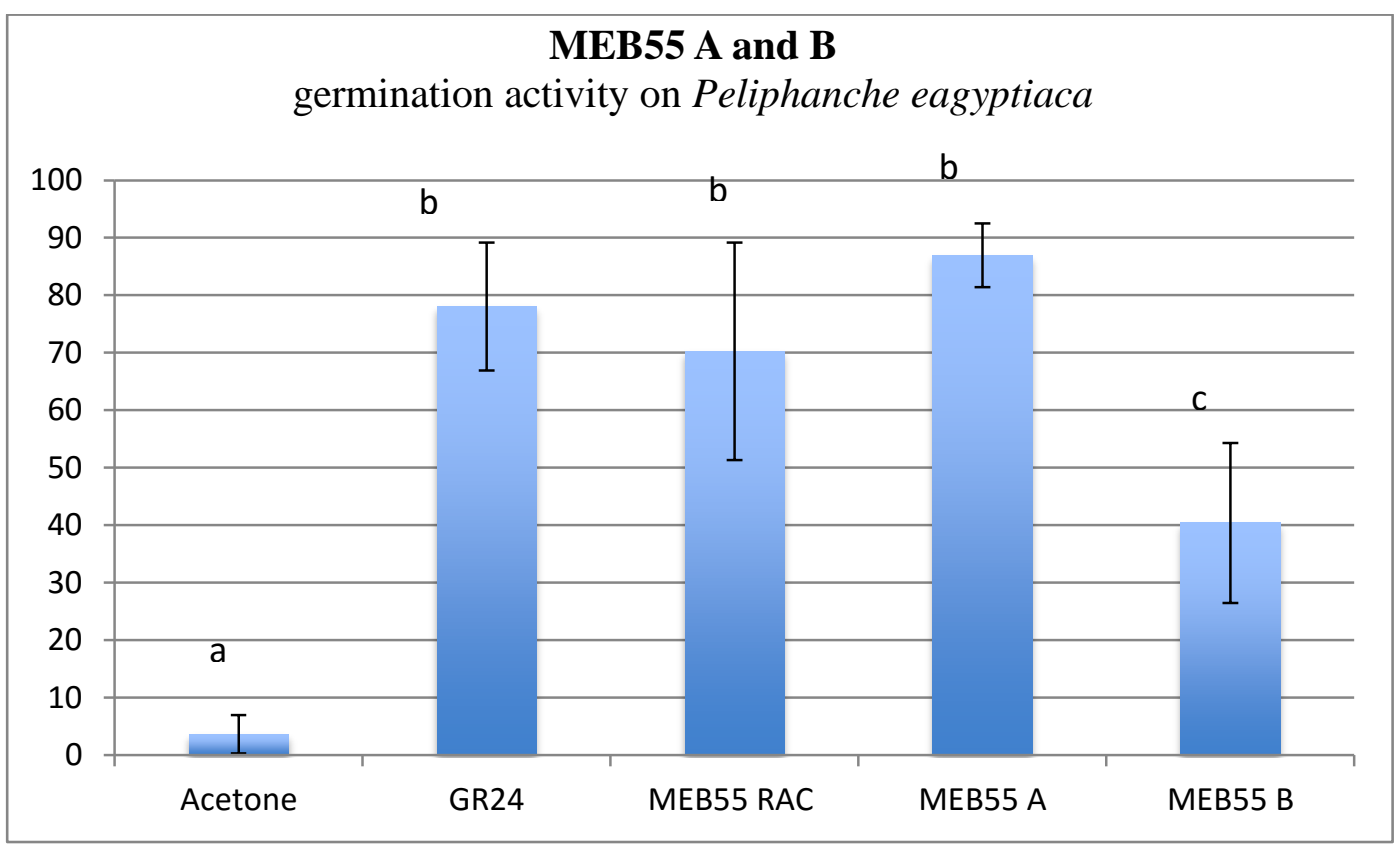

10 Figure 8. Bar graph representation of percentages of germinated ( $\mathrm{Y}$ axis) of Peliphanche 11 aegyptiaca seeds after exposure to pure enantiomers of MEB55 A $(7, R)$ and $\mathbf{B}(\mathbf{8 ,}, S)$ at $0.1 \mu \mathrm{M}$ 12 concentration.

13

14 We recently reported the antiproliferative activity of some SL analogues. ${ }^{9}$ After an initial 15 screening of EGO10 derivatives with various substitutions on the A ring, those with a thienyl 
1 (MEB55) and dioxathienyl substituent at $\mathrm{C}-7$ were found to be the most potent and promising

2 candidates for anticancer therapy due to their ability to specifically induce cell cycle arrest,

3 cellular stress, and apoptosis in cancer line cell with minimal effects on normal cells growth and

4 survival. Two different cell lines have been tested for their response to enantiopure SL

5 analogues. The first line $\mathrm{BJ}$ is a normal cell line established from human neonate fibroblasts

6 (skin, foreskin), while the second MDA-MB-231 is from human breast cancer cells (epithelial,

7 adenocharcinoma disease). ${ }^{9}$ Enantiomer activity on cell lines was quantified as the effect on cell

8 viability, using XTT (see Experimental Section). As shown in Figure 9, the normal cell line BJ is

9 insensitive to the application of SL analogue application while the viability of the tumour cell

10 line MDA-MB-231 is affected by SLs. In particular, one of the two enantiomers MEB55 A (7),

11 which corresponds to the 2 'R configuration (red bar, Figure 7) was found to be much more active

12 than the S stereoisomer. The racemic mixture (purple bar, Figure 9) and the equimolar mixture

13 of $R$ and $S$ enantiomers, created in order to have an additional control (light blue), show activity

14 which is similar to the most active $R$ enantiomer indicating that the $S$ enantiomer does not 15 possess antagonist activity. 


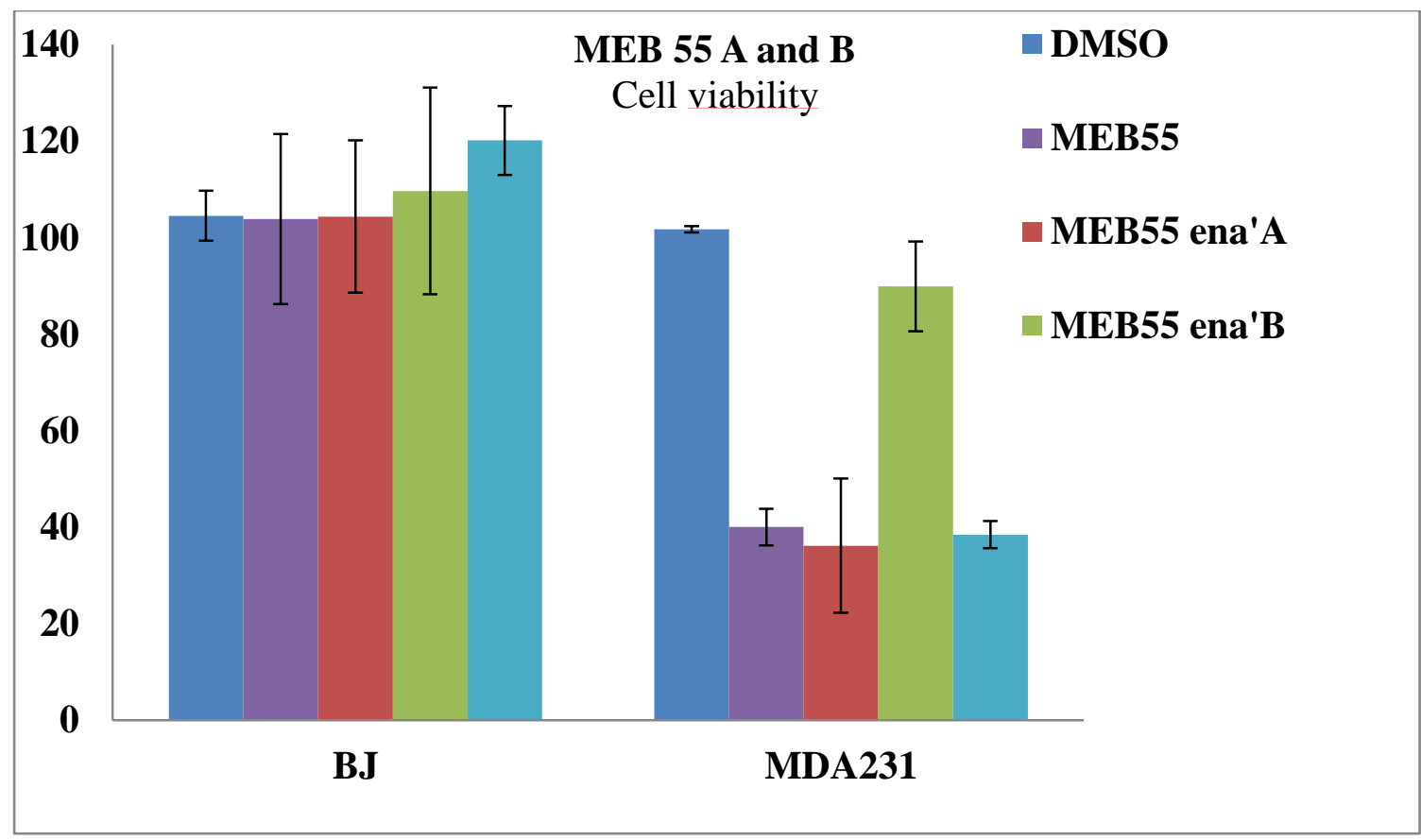

2 Figure 9. Bar graph representation of cell viability test on cell lines BJ and MDA-MB-231 in the

3 presence of MEB55 (2500 were seeded per line). These were treated with a $7.5 \mu \mathrm{M}$ solution of

4 compound MEB55 after one day. XTT measurements for the determination of cell viability were

5 carried out 48h-after exposure to compound MEB55.

6 EGOBP. Spatial hormone distribution is actively regulated by plants at multiple levels, such as

7 biosynthesis, catabolism, and transport to allow specific function to occur. The level of SL

8 secretion is also likely to be properly controlled. The Petunia hybrid ABC transporter PDR1 has

9 recently been isolated. ${ }^{35}$ However, only little is known about the dynamic distribution of SLs,

10 their precursors, and their derivatives in Arabidopsis in particular. ${ }^{36}$ As part of our work on the

11 synthesis of fluorescent tagged SL analogues to map the distribution of SLs in plants we

12 synthesized EGO10 derivatives by linking the EGO10 core to a fluorescent BODIPY based

13 probe, through a 3-carbon linker (Figure 2, EGO BP A 9 and EGO BP B 10). The activity of

14 racemic EGO BP had previously been tested on Peliphanche aegyptiaca seeds and found to be a 
1 little lower than rac-GR24, ${ }^{20}$ as expected. Racemic EGOBP was resolved in the two enantiomers

2 EGOBP A (9) and EGOBP B (10) whose absolute configuration was unambiguously assessed

3 according to ECD data and chiral HPLC behaviour (SI); EGOBP A being the $R$ and EGOBP B

4 the $S$ enantiomer. Fluorescence emission measurements of $A$. thaliana seedlings treated with

5 fluorescent SLs showed a higher accumulation of EGOBP A than EGOBP B in the root.

6 Moreover EGOBP A was the most active root hair elongation analogue. Controls were

7 performed using fluorophore BODIPY(naked-BP) alone which led to non-specific tissue

8 distribution and with EGOBP which was missing the D-ring and the enol ether connecting bridge

9 which also lead to nonspecific distribution. Given these preliminary but clear-cut results EGOBP

10 A was then chosen as the lead candidate with which to follow the distribution and transport of

11 SLs in Arabidopsis. ${ }^{37}$

12 BPGR24. Because of its widespread use and the huge body of data available on its biological 13 activity in different organisms we functionalized the universal standard GR24 with the same 14 fluorescent probes BODIPY and assessed the bioactivity of the four stereoisomers (Figure 2).

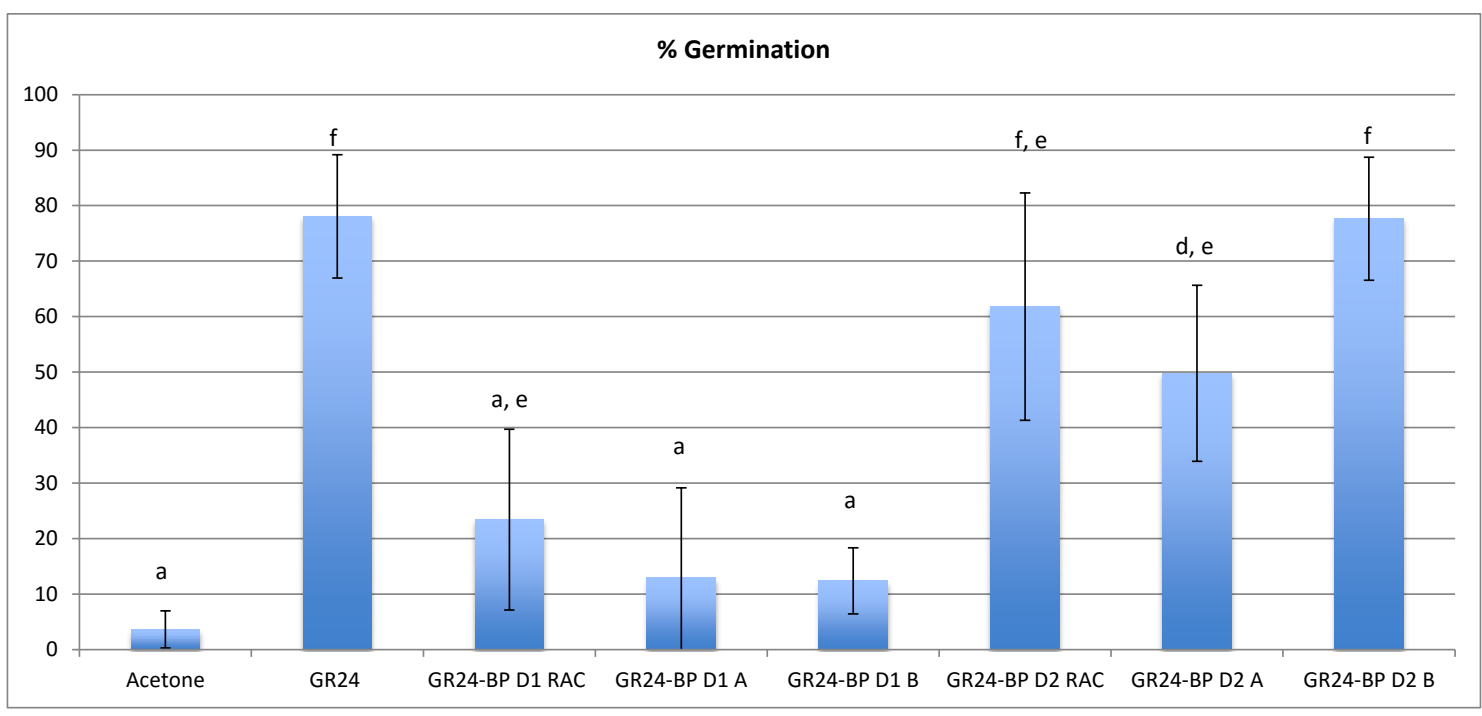


1 Figure 10. Bar graph representation of percentages of germinated seeds ( $\mathrm{Y}$ axis) of Peliphanche

2 aegyptiaca after exposure to pure enantiomers of the GR24 BP serie at $0.1 \mu \mathrm{M}$ concentration

3 The germination stimulatory activity of all four GR24 BP stereoisomers was measured towards

4 Peliphanche aegyptiaca seeds. The results shown in Figure 10 surprisingly revealed that the D1

5 diastereoisomer is completely inactive and statistically comparable to the negative control

6 acetone, whether used as a racemic mixture or a pure enantiomer. It is worthwhile emphasizing

7 that GR24, whether used as a racemic or a pure enantiomer (rac-GR24 vs. (+) GR24 and (-) ent

8 GR24) shows the predicted germination activity. Besides, the D2 diasteroisomers show

9 germination activity that is comparable to rac-GR24 both as racemate and as pure enantiomer

10 (2'-epi BPGR24 14 and ent-2'-epi GR24BP 13). This was then chosen as the lead candidate for

11 bioimaging studies into SL transport and distribution in living organisms. ${ }^{38}$

12 In this study, the absolute configuration of a series of enantiomerically pure SL analogues by

13 means of X-ray analyses of one of the compounds and by the comparative analysis of the ECD

14 spectra of all family members were elucidated. This was based on the fine correlations found

15 within the whole family of compounds and with the literature data.

16 Recent findings demonstrate that configuration at $\mathrm{C}-2^{\prime}$ position (D-ring) plays a crucial role in

17 the activation of specific SL related responses. ${ }^{32}$ As configuration has been proven to be a

18 significant determinant of SL activity, we examined multiple physiological responses in various

19 organisms in order to correlate absolute configuration to activity. We use parasitic seeds

20 germination (Peliphanche aegyptiaca), hyphal branching (Gigaspora margarita), root elongation

21 (Arabidopsis thaliana), and cell cycle arrest of cancer and non-cancer cell lines as the biological

22 targets. Wherever selectivity towards one of the two enantiomers is observed, the enantiomer 
1 with $2^{\prime} R$ configuration is the most active. In the Orobanchaceae, S. hermontica seeds are reported

2 to respond to all stereoisomers of GR $24^{1 \mathrm{a}}$ and deoxystrigol ${ }^{30}$ with a slight preference for isomers

3 with the same configuration as natural strigol. The four stereoisomers of deoxystrigol have

4 recently been tested on Orobanche minor and it was found that the stereoisomer with the same

5 configuration as orobanchol was the most active while its enantiomer the least so. ${ }^{32}$ However, 2 '-

6 epi BPGR24 $\left(\mathbf{1 4}, 2^{\prime}, S\right)$ is the most active fluorescent derivative of GR24.

7 In summary, the present work represents an elucidation of the absolute configurations of some of

8 the most potent SL analogues that have been designed for specific purposes, and the correlation

9 between stereochemistry and biological response.

\section{EXPERIMENTAL SECTION}

11 General Experimental Procedures. ${ }^{1} \mathrm{H}$ NMR and ${ }^{13} \mathrm{C}$ NMR spectra were recorded on a Bruker

12 Avance-200 spectromer. ${ }^{1} \mathrm{H}$ NMR spectra were recorded at $200 \mathrm{MHz},{ }^{13} \mathrm{C}$ NMR and DEPT

13 spectra at $50 \mathrm{MHz}$. ESIMS data were recorded using an LCQ Deca XP plus spectrometer

14 (Thermo) spectrometer with an electrospray interface and ion trap as a mass analyzer; sheath gas

15 flow rate was set at 25 (arbitrary unit), auxiliary gas flow rate at 5 (arbitrary unit), spray voltage

16 at $3.25(\mathrm{KV})$, capillary temperature at $270{ }^{\circ} \mathrm{C}$, capillary voltage at $-7(\mathrm{~V})$, and tube lens offset at

$17-60.00(\mathrm{~V})$. Nitrogen was used as a sheath and auxiliary gas. HRMS data were recorded on an

18 LTQ Orbitrap Hybrid Mass Spectrometer. MS data were recorded at an ionizing voltage of 70

$19 \mathrm{eV}$. Chromatographic separations were carried out on silica gel (Merck Grade 7734, pore size 60

$20 \AA$, 70-230 mesh); Rf values refer to TLC carried out on 0.25-mm silica gel plates (Merck F254),

21 with the same eluent indicated for the column chromatography. The enantiomers were separated

22 on either a semi-preparative and an analytical Chiralpak IC column (particle size $5 \mu \mathrm{m}$, Daicel, 
1 Osaka, Japan). Dimensions: Analytical column $4.6 \Phi$ x $250 \mathrm{mmL}$; Semiprep. column $10 \Phi$ x

$2250 \mathrm{mmL}$. All the chemicals were purchased from Sigma-Aldrich and were used as received

3 unless stated otherwise. Column chromatography purifications was performed via classical

4 chromatography. Compounds $15,17,18$, and 19 were synthesized as previously reported. ${ }^{25}$ The

5 glassware used for classical syntheses was heated overnight in an oven at $150^{\circ} \mathrm{C}$ and assembled

6 in the oven, then cooled under argon flux before starting the reactions. A Jasco P-2000

7 polarimeter was used for the determination of optical rotations. ECD measurements were

8 performed on a JASCO J-815 instrument at RT, in quartz cells with $1 \mathrm{~mm}$ optical path; scanning

9 speed $100 \mathrm{~nm} / \mathrm{min}$, bandwidth $1 \mathrm{~nm}$.

10 Biological Tests. Plant material. Seeds of Peliphanche aegyptiaca were collected from field

11 grown tomato in the West Galilee in Israel. The seeds were stored in glass vials in the dark at

12 room temperature until used in germination tests. Preparation of test solutions: the compound to

13 be tested were weighted out accurately and dissolved in $1 \mathrm{~mL}$ of acetone and then diluted with

14 sterile distilled $\mathrm{H}_{2} \mathrm{O}$ to reach the appropriate concentrations. All solutions were prepared just

15 before use. Seeds were surface sterilized and preconditioned according to the experimental

16 procedure indicated in ref. 31 . Briefly, seeds were exposed to $50 \%(\mathrm{v} / \mathrm{v})$ aqueous solutions of

17 commercial bleach for 5 min (2\% hypochlorite) and rinsed with sterile distilled $\mathrm{H}_{2} \mathrm{O}$. For

18 preconditioning, seeds were sown on a glass fibre filter paper disc using a sterile toothpick

19 (approximately 20 seeds per disc), the glass fibre discs were placed on 2 filter paper discs,

20 dampened with sterile distilled $\mathrm{H}_{2} \mathrm{O}$ and incubated at $25{ }^{\circ} \mathrm{C}$ in the dark for 6 days. The

21 preconditioned seeds were then allowed to dry completely in the laminar flow, treated with the

22 strigolactone analogue solutions and germination rate was evaluated under a stereomicroscope 7

23 days after treatment. At least 100 seeds were analyzed at each concentration, synthetic 
1 strigolactone GR24 $10^{-7} \mathrm{M}$ was included as the positive control while an aqueous solution of

$20.1 \%$ acetone and sterile distilled $\mathrm{H}_{2} \mathrm{O}$ was included as the negative control. Seeds were

3 considered to be germinated if the radicle protruded through the seed coat.

4 Fungal Material. Spores of Gigaspora margarita Becker and Hall were collected from a

5 previously established trap culture of clover, sterilized with a solution of chloramine $\mathrm{T}(3 \% \mathrm{P} / \mathrm{V})$

6 and streptomycine sulphate $(0,03 \% \mathrm{P} / \mathrm{V})$, rinsed with distilled $\mathrm{H}_{2} \mathrm{O}$ and placed in a Petri plate

7 filled with $0.2 \%$ Phytagel gel (Sigma-Aldrich) containing $3 \mathrm{mM} \mathrm{MgSO}$. The plates were

8 incubated vertically for 5 days at $30{ }^{\circ} \mathrm{C}$ in the dark. Paper discs (6 mm diameter), loaded with the

9 strigolactone analogue solution, were positioned on either side of the germinating hyphae tips.

10 The number of newly formed hyphal apex was recorded $24 \mathrm{~h}$ after treatment. GR24 $10^{-7} \mathrm{M}$ was

11 included as positive control, while an aqueous solution of $0.1 \%$ acetone and sterile distilled $\mathrm{H}_{2} \mathrm{O}$

12 was included as negative control.

13 XTT Cell Proliferation Assay. Cells were seeded into a 96 well plates at 2,500 cells per well in

14 triplicates in normal growing media. The following day, the media was replaced with phenol red-

15 free DMEM supplemented with 10\% FBS (Foetal Bovine Serume) and 5\% penicillin-

16 streptomycin solution. Cells were incubated over night at $37{ }^{\circ} \mathrm{C}$ in a humidified $5 \% \mathrm{CO}_{2}-95 \%$

17 air atmosphere, and then were treated as indicated below for 48h. An XTT (2, 3,-bis(2-methoxy-

18 4-nitro-5-sulfophenyl)-5-[(phenylamino)carbonyl]-2H-tetrazolium inner salt) reduction was used

19 to quantify viability according to manufacturer's instruction (Biological industries, IL). Cells

20 were incubated with XTT reagent for $2 \mathrm{~h}$ at $37^{\circ} \mathrm{C}$ in a humidified $5 \% \mathrm{CO}-95 \%$ air atmosphere.

21 Absorbance was recorded on a VersaMax ELISA Microplate Reader (Molecular devises, USA)

22 at $450 \mathrm{~nm}$ with $650 \mathrm{~nm}$ being the reference wavelength. Cell survival was estimated from the

23 equation: \% cell survival of control= $100 \times($ At-Ac) $($ treatment $) /($ At-Ac) $($ control $)$, where At and 
1 Ac are the absorbencies (450nm) of the XTT colorimetric reaction in treated and control cultures

2 respectively minus non-specific absorption measured at $650 \mathrm{~nm}$. Absorbance of the medium

3 alone was also deducted from specific readings. Data points were connected by non-linear

4 regression lines of the sigmoidal dose-response relation in dose response assays.

5 7-Amino-3,3a,4,8b-tetrahydro-2H-indeno[1,2-b]furan-2-one (16): A solution of 15 (3.12 mmol,

$6 \quad 0.684 \mathrm{~g})$ in $4.8 \mathrm{~mL}$ of $\mathrm{EtOH}$ was added to an aqueous solution of $\mathrm{CaCl}_{2}(2.18 \mathrm{mmol}, 0.684$ gin

$73.6 \mathrm{~mL}$ of water) in a three-necked round bottom flask. Zn powder was then added (27.52 mmol,

$8 \quad 1.80$ gr) and the resulting suspension was heated to reflux temperature $\left(80^{\circ} \mathrm{C}\right)$ and reacted for 2

9 hours. Upon TLC control (petroleum ether/EtOAc, 1/1, Rf $=0.21$ ), which indicated the total

10 consumption of the starting material, the reaction mixture was filtered on a Büchner funnel and

11 washed with $\mathrm{CH}_{2} \mathrm{Cl}_{2}$. The organic phases were washed with brine (1x $\left.25 \mathrm{~mL}\right)$ and $\mathrm{H}_{2} \mathrm{O}(2 \times 25$

$12 \mathrm{ml}$ ), dried over $\mathrm{K}_{2} \mathrm{CO}_{3}$, filtered and the solvent was evaporated. Compound 2 [0.420 g (80\%

13 yield)] was obtained as a whitish solid and did not require further purification. ${ }^{1} \mathrm{H}$ NMR $\left(\mathrm{CDCl}_{3}\right.$,

$14200 \mathrm{MHz}): \delta 2.30(1 \mathrm{H}, \mathrm{dd}, \mathrm{J}=18 \mathrm{~Hz}, \mathrm{~J}=5.8 \mathrm{~Hz}, \mathrm{H} 3 \mathrm{a}), 2.63-2.86(2 \mathrm{H}, \mathrm{m}, \mathrm{H} 3), 3.05-3-51(2 \mathrm{H}$,

$15 \mathrm{~m}, \mathrm{H} 4), 3.57\left(2 \mathrm{H}, \mathrm{br}, \mathrm{NH}_{2}\right), 5.73(1 \mathrm{H}, \mathrm{d}, \mathrm{J}=7.0 \mathrm{~Hz}, \mathrm{H} 8 \mathrm{~b}), 6.61(1 \mathrm{H}, \mathrm{dd}, \mathrm{J}=2.0 \mathrm{~Hz}, \mathrm{~J}=8.0 \mathrm{~Hz}$,

$16 \mathrm{H6}), 6.71(1 \mathrm{H}, \mathrm{d}, \mathrm{J}=2.0 \mathrm{~Hz}, \mathrm{H} 8), 6.98(1 \mathrm{H}, \mathrm{d}, \mathrm{J}=8.4 \mathrm{~Hz}, \mathrm{H} 5)$. Spectroscopic data correspond

17 to literature reports. ${ }^{39}$ 
1 rac-BPGR24 (and rac 2'-epi BPGR24). A solution of $\mathbf{2 0}^{21 \mathrm{~b}}(0.15 \mathrm{mmol}, 50 \mathrm{mg})$ was prepared

2 in $3 \mathrm{~mL}$ of DCM in a three neck round bottom flask, 2-chloro-4,6-dimethoxy-1,3,5-triazine

3 (CDMT, $0.18 \mathrm{mmol} 32 \mathrm{mg}$ ) was then added and the solution was cooled to $-5^{\circ} \mathrm{C} . \mathrm{N}$ -

4 methylmorpholine (NMM) was added and the mixture reacted for 2 hours. When the TLC

5 control ( petroleum ether/ EtOAc 2:3) confirmed the formation of the activated BODIPY

6 complex (approximately $2 \mathrm{~h}$ ) rac- amino- GR24 19 (or rac- 2'-epi- GR24, $0.150 \mathrm{mmol} 47 \mathrm{mg}$ )

7 was added via cannula. The mixture was reacted at room temperature overnight. A $10 \%$ solution

8 of citric acid was added and the aqueous phases extracted with DCM $(10 \mathrm{~mL} \times 3)$. The organic

9 phases were then dried over $\mathrm{Na}_{2} \mathrm{SO}_{4}$, and the solvent evaporated under reduced pressure. The

10 crude was purified by flash chromatography with hexanes/EtOAc 2:3 ( $\operatorname{Rf} 0.20$ green

11 fluorescence) to give $74 \mathrm{mg}$ (78\% yield) of an orange solid of BPGR24/ent-BPGR24.

12 Separation on chiral HPLC gives pure enantiomers.

13 BPGR24 (11): $[\alpha]^{25} \mathrm{D}+86\left(c 0.2, \mathrm{CH}_{2} \mathrm{Cl}_{2}\right) .{ }^{1} \mathrm{H} \mathrm{NMR}\left(\mathrm{CDCl}_{3}, 200 \mathrm{MHz}\right): \delta_{\mathrm{H}} 2.04\left(5 \mathrm{H}, \mathrm{s}, \mathrm{CH}_{3} \mathrm{D}\right.$

14 ring and $\left.\mathrm{CH}_{2}\right), 2.39-2.49\left(14 \mathrm{H}, \mathrm{m}, \mathrm{CH}_{3}\right.$ BODIPY and $\left.\mathrm{CH}_{2}\right), 2.98-3.06\left(3 \mathrm{H}, \mathrm{m}, \mathrm{H} 4\right.$ and $\left.\mathrm{CH}_{2}\right)$,

15 3.29-3.42 (1H, m, H4), 3.88-3.97 (1H, m, H3a), $5.88(1 \mathrm{H}, \mathrm{d}, J=7.8 \mathrm{~Hz}, \mathrm{H} 8 \mathrm{~b}), 6.03(2 \mathrm{H}, \mathrm{s}$,

16 BODIPY), $6.17(1 \mathrm{H}, \mathrm{br}, \mathrm{H} 3$ '), $6.96(1 \mathrm{H}, \mathrm{br}, \mathrm{H} 2$ '), $7.13(1 \mathrm{H}, \mathrm{d}, J=8.0 \mathrm{~Hz}, \mathrm{H} 5), 7.47-7.56(3 \mathrm{H}$,

$17 \mathrm{~m}, \mathrm{H} 6, \mathrm{H} 6{ }^{\prime}$ and $\left.\mathrm{H} 8\right) .{ }^{13} \mathrm{C}$ NMR $\left(\mathrm{CDCl}_{3}, 50 \mathrm{MHz}\right): \delta_{\mathrm{C}} 10.7\left(2 \mathrm{CH}_{3}\right.$ BODIPY $), 14.4\left(2 \mathrm{CH}_{3}\right.$

18 BODIPY), $16.4\left(\mathrm{CH}_{3}\right.$ D- ring), $27.2\left(\mathrm{CH}_{2} \mathrm{CH}_{2} \mathrm{CH}_{2} \mathrm{CONH}\right), 27.4\left(\mathrm{CH}_{2} \mathrm{CH}_{2} \mathrm{CONH}\right), 36.9$

$19\left(\mathrm{CH}_{2} \mathrm{CH}_{2} \mathrm{CH}_{2} \mathrm{CONH}\right), 37.0\left(\mathrm{CH}_{2} \mathrm{C}-4 \mathrm{a}\right), 39.2$ (C-3a), 85.9 (C-8b), 100.7 (C-2'), 113.2 (C-4),

20117.5 (C-3’), 121.8 (CH-BODIPY), 122.3 (phenyl $C$-5), 125.6 (C-6'), 131.5 (phenyl, C-3), 135.9

21 (2C, BODIPY), 137.5 (2C, BODIPY), 138.2 (C, BODIPY), 139.3 (2C, BODIPY), 140.7 (C-4a),

22141.0 (phenyl, C-6), 145.3 (C-8a), 151.3 (phenyl, C-8), 154.0 (C-7), 170.2, 171.5 (CONH);

23 ESIMS $m / z$ 652,3 [M+Na] $]^{+}$; HRESIMS $m / z 629.2339$ (calcd for $\mathrm{C}_{34} \mathrm{H}_{34} \mathrm{BF}_{2} \mathrm{~N}_{3} \mathrm{O}_{6}: 629,2509$ ). 
1 ent-BPGR24 (12): $[\alpha]^{25}{ }_{\mathrm{D}}-82\left(c 0.2, \mathrm{CH}_{2} \mathrm{Cl}_{2}\right) .{ }^{1} \mathrm{H}$ NMR $\left(\mathrm{CDCl}_{3}, 200 \mathrm{MHz}\right): \delta_{\mathrm{H}} 2.05\left(5 \mathrm{H}, \mathrm{s}, \mathrm{CH}_{3}\right.$

2 D ring and $\left.\mathrm{CH}_{2}\right), 2.39-2.51\left(14 \mathrm{H}, \mathrm{m}, \mathrm{CH}_{3} \mathrm{BODIPY}\right.$ and $\left.\mathrm{CH}_{2}\right), 2.98-3.06\left(3 \mathrm{H}, \mathrm{m}, \mathrm{H} 4\right.$ and $\left.\mathrm{CH}_{2}\right)$,

3 3.30-3.43 (1H, m, H4), 3.90-3.98 (1H, m, H3a), $5.90(1 \mathrm{H}, \mathrm{d}, J=7.8 \mathrm{~Hz}, \mathrm{H} 8 \mathrm{~b}), 6.04(2 \mathrm{H}, \mathrm{s}$,

4 BODIPY), 6.19 (1H, br, H3'), 6.99 (1H, br, H2'), 7.14 (1H, d, $J=8.0 \mathrm{~Hz}, \mathrm{H} 5), 7.50-7.57$ (3H,

$5 \mathrm{~m}, \mathrm{H} 6, \mathrm{H} 6{ }^{\prime}$ and $\left.\mathrm{H} 8\right) .{ }^{13} \mathrm{C}$ NMR $\left(\mathrm{CDCl}_{3}, 50 \mathrm{MHz}\right): \delta_{\mathrm{C}} 10.9\left(2 \mathrm{CH}_{3} \mathrm{BODIPY}\right), 14.6\left(2 \mathrm{CH}_{3}\right.$

6 BODIPY), $16.5\left(\mathrm{CH}_{3}\right.$ D- ring), $27.5\left(\mathrm{CH}_{2} \mathrm{CH}_{2} \mathrm{CH}_{2} \mathrm{CONH}\right), 27.6\left(\mathrm{CH}_{2} \mathrm{CH}_{2} \mathrm{CONH}\right), 37.1$

$7 \quad\left(\mathrm{CH}_{2} \mathrm{CH}_{2} \mathrm{CH}_{2} \mathrm{CONH}\right), 37.2\left(\mathrm{CH}_{2} \mathrm{C}-4 \mathrm{a}\right), 39.3$ (C-3a), 86.2 (C-8b), 100.9 (C-2'), 113.4 (C-4),

8117.7 (C-3’), 121.9 (CH-BODIPY), 122.5 (phenyl C-5), 125.7 (C-6'), 131.7 (phenyl, C-3), 136.0

9 (2C, BODIPY), 137.7 (2C, BODIPY), 138.3 (C, BODIPY), 139.4 (2C, BODIPY), 140.9 (C-4a),

10141.2 (phenyl, C-6), 145.6 (C-8a), 151.6 (phenyl, C-8), 154.1 (C-7), 170.4, 171.8 (CONH);

11 ESIMS $m / z$ 652,3 [M+Na] ${ }^{+}$; HRESIMS $m / z 629.1416$ (calcd for $\mathrm{C}_{34} \mathrm{H}_{34} \mathrm{BF}_{2} \mathrm{~N}_{3} \mathrm{O}_{6}: 629,2509$ ).

12 2'-epi-BPGR24 (14): $[\alpha]^{25}{ }_{\mathrm{D}}+148\left(\right.$ c $\left.0.2, \mathrm{CH}_{2} \mathrm{Cl}_{2}\right) .{ }^{1} \mathrm{H} \mathrm{NMR}\left(\mathrm{CDCl}_{3}, 200 \mathrm{MHz}\right): \delta_{\mathrm{H}} 2.05(3 \mathrm{H}, \mathrm{s}$,

$13 \mathrm{CH}_{3} \mathrm{D}$ ring), 2.42-2.51 (16H, m, $\mathrm{CH}_{3}$ BODIPY and $\left.2 \mathrm{xCH}_{2}\right), 3.02-3.10\left(3 \mathrm{H}, \mathrm{m}, \mathrm{H} 4\right.$ and $\left.\mathrm{CH}_{2}\right)$,

14 3.32-3.45 (1H, m, H4), 3.90-4.01 (1H, m, H3a), $5.91(1 \mathrm{H}, \mathrm{d}, J=7.8 \mathrm{~Hz}, \mathrm{H} 8 \mathrm{~b}), 6.04(2 \mathrm{H}, \mathrm{s}$,

15 BODIPY), $6.18(1 \mathrm{H}, \mathrm{br}, \mathrm{H} 3$ '), $6.97(1 \mathrm{H}, \mathrm{br}, \mathrm{H} 2$ '), $7.16(1 \mathrm{H}, \mathrm{d}, J=8.0 \mathrm{~Hz}, \mathrm{H} 5), 7.46-7.61(3 \mathrm{H}$,

$16 \mathrm{~m}, \mathrm{H} 6, \mathrm{H} 6{ }^{\prime}$ and $\left.\mathrm{H} 8\right) .{ }^{13} \mathrm{C}$ NMR $\left(\mathrm{CDCl}_{3}, 50 \mathrm{MHz}\right): \delta_{\mathrm{C}} 10.9\left(2 \mathrm{CH}_{3} \mathrm{BODIPY}\right), 14.6\left(2 \mathrm{CH}_{3}\right.$

17 BODIPY), $16.5 \quad\left(\mathrm{CH}_{3}\right.$ D-ring), $27.4 \quad\left(\mathrm{CH}_{2} \mathrm{CH}_{2} \mathrm{CH}_{2} \mathrm{CONH}\right), 27.6 \quad\left(\mathrm{CH}_{2} \mathrm{CH}_{2} \mathrm{CONH}\right), \quad 37.1$

$18\left(\mathrm{CH}_{2} \mathrm{CH}_{2} \mathrm{CH}_{2} \mathrm{CONH}\right), 37.2\left(\mathrm{CH}_{2} \mathrm{C}-4 \mathrm{a}\right), 39.3$ (C-3a), 86.1 (C-8b), 100.9 (C-2'), 113.4 (C-4),

19117.7 (C-3'), 121.9 (CH-BODIPY), 122.5 (phenyl C-5), 125.8 (C-6’), 131.7 (phenyl, C-3), 136.1

20 (2C, BODIPY), 137.6 (2C, BODIPY), 138.4 (C, BODIPY), 139.5 (2C, BODIPY), 140.8 (C-4a),

21141.2 (phenyl, C-6), 145.5 (C-8a), 151.5 (phenyl, C-8), 154.2 (C-7), 170.4, 171.7 (CONH);

22 ESIMS $m / z$ 652,2 [M+Na] $]^{+}$; HRESIMS $m / z$ 629,3516 (calcd for $\mathrm{C}_{34} \mathrm{H}_{34} \mathrm{BF}_{2} \mathrm{~N}_{3} \mathrm{O}_{6}: 629,2509$ ). 
1 ent-2'epi-BPGR24 (13): $[\alpha]^{25}{ }_{\mathrm{D}}-175\left(\right.$ c $\left.0.1, \mathrm{CH}_{2} \mathrm{Cl}_{2}\right) .{ }^{1} \mathrm{H} \mathrm{NMR}\left(\mathrm{CDCl}_{3}, 200 \mathrm{MHz}\right): \delta_{\mathrm{H}} 2.01(3 \mathrm{H}$,

2 s, $\mathrm{CH}_{3} \mathrm{D}$ ring), 2.38-2.48 (16H, m, $\mathrm{CH}_{3}$ BODIPY and 2xCH$), 2.98-3.04\left(3 \mathrm{H}, \mathrm{m}, \mathrm{H} 4\right.$ and $\left.\mathrm{CH}_{2}\right)$,

3 3.29-3.40 (1H, m, H4), 3.87-3.98 (1H, m, H3a), $5.88(1 \mathrm{H}, \mathrm{d}, J=7.8 \mathrm{~Hz}, \mathrm{H} 8 \mathrm{~b}), 6.01(2 \mathrm{H}, \mathrm{s}$,

4 BODIPY), $6.15(1 \mathrm{H}, \mathrm{br}, \mathrm{H} 3$ '), $6.94(1 \mathrm{H}, \mathrm{br}, \mathrm{H} 2$ ') $7.13(1 \mathrm{H}, \mathrm{d}, J=8.0 \mathrm{~Hz}, \mathrm{H} 5), 7.43-7.58$ (3H,

$5 \mathrm{~m}, \mathrm{H} 6, \mathrm{H} 6{ }^{\prime}$ and $\left.\mathrm{H} 8\right) .{ }^{13} \mathrm{C}$ NMR $\left(\mathrm{CDCl}_{3}, 50 \mathrm{MHz}\right): \delta_{\mathrm{C}} 10.9\left(2 \mathrm{CH}_{3}\right.$ BODIPY $), 14.6\left(2 \mathrm{CH}_{3}\right.$

6 BODIPY), $16.6 \quad\left(\mathrm{CH}_{3}\right.$ D-ring), $27.5 \quad\left(\mathrm{CH}_{2} \mathrm{CH}_{2} \mathrm{CH}_{2} \mathrm{CONH}\right), 27.6 \quad\left(\mathrm{CH}_{2} \mathrm{CH}_{2} \mathrm{CONH}\right), \quad 37.0$

$7\left(\mathrm{CH}_{2} \mathrm{CH}_{2} \mathrm{CH}_{2} \mathrm{CONH}\right), 37.2\left(\mathrm{CH}_{2} \mathrm{C}-4 \mathrm{a}\right), 39.5(\mathrm{C}-3 \mathrm{a}), 86.0(\mathrm{C}-8 \mathrm{~b}), 100.8(\mathrm{C}-2$ '), 113.2 (C-4),

8117.7 (C-3’), 121.9 (CH-BODIPY), 122.4 (phenyl C-5), 125.7 (C-6'), 131.7 (phenyl, C-3), 136.2

9 (2C, BODIPY), 137.8 (2C, BODIPY), 138.4 (C, BODIPY), 139.6 (2C, BODIPY), 140.8 (C-4a),

10141.1 (phenyl, C-6), 145.5 (C-8a), 151.4 (phenyl, C-8), 154.2 (C-7), 170.4, 171.6 (CONH).;

11 ESIMS $m / z$ 652,2 [M+Na] $]^{+}$; HRESIMS $m / z 629,2211$ (calcd for $\mathrm{C}_{34} \mathrm{H}_{34} \mathrm{BF}_{2} \mathrm{~N}_{3} \mathrm{O}_{6}: 629,2509$ ).

12 X-ray Analysis. Crystals that were suitable for X-ray diffraction analyses were obtained via the

13 slow evaporation of a methanol solution. X-ray data were collected on an Oxford Diffraction

14 Gemini R-Ultra diffractometer equipped Enhanced Ultra $(\mathrm{Cu})$ X-ray Source (mirror

15 monochromatized $\mathrm{Cu}-\mathrm{K} \alpha$ radiation, $\lambda=1.5418 \AA$ ). The $\omega$ scan was performed with a frame width

16 of $1.0^{\circ}$. The intensities were corrected for absorption with the numerical correction based on a

17 Gaussian integration over a multifaceted crystal model. Softwares used: CrysAlisPro (Agilent

18 Technologies, Version 1.171.37.31) for data collection, data reduction and absorption correction;

19 SHELXT $^{40}$ for data solution; SHELXL-2014/7 ${ }^{40}$ for refinement; OLEX2 (version 1.2.5) ${ }^{41}$ for

20 structure analysis and drawing preparation. All non-hydrogen atoms were anisotropically refined.

21 Hydrogen atoms were calculated and refined riding with $\mathrm{U}_{\mathrm{iso}}=1.2$ or $1.5 \mathrm{U}_{\text {eq }}$ of the atom

22 connected. The absolute configuration was determined using Parson's method (Flack parameter

23 is reported on S20 of the Supporting Information). ${ }^{27}$ 


\section{ASSOCIATED CONTENT}

\section{Supporting Information}

3 The supporting information is available free of charge on the ACS Publication website at DOI:

$4 \quad{ }^{1} \mathrm{H}$ and ${ }^{13} \mathrm{C}$ NMR spectra, ECD spectra, $[\alpha]^{\mathrm{D}}$ data, details and CIF file of X-ray data. The

\section{AUTHOR INFORMATIONS}

\section{Corresponding Author}

$7 \quad *$ E-mail: cristina.prandi@ unito.it (C. Prandi).

$8 \quad *$ Tel: (+39) 0116707647.

9 Notes

10 The authors declare no competing financial interest.

\section{ACKNOWLEDGMENTS}

13 We thank the Cost Association STREAM FA1206 "Strigolactones: biological roles and

14 applications", Compagnia di San Paolo Foundation for their support (proJect SLEPS), the 15 Lagrange ProJect - CRT Foundation/ISI for their grant, the Italian Ministry of Universities and

16 Research and the Regione Piemonte. EGO thanks the European Commission for a Marie Curie 17 fellowship (FP7-PEOPLE-2012-ITN, project ECHONET "Expanding capability in Heterocyclic 18 Organic Synthesis”, project number 316379). 


\section{REFERENCES}

(1) (a) Zwanenburg, B.; Pospíšil, T. Mol. Plant 2013, 6, 38-62;

(b) Ćavar, S.;

4 Zwanenburg, B.; Tarkowski, P. Phyt. Rev. 2014, 691-711; (c) Yoneyama, K.; Xie, X.;

5 Yoneyama, K.; Takeuchi, Y. Pest Manag. Sci. 2009, 65, 467-470.

(2) (a) Gomez-Roldan, V.; Fermas, S.; Brewer, P. B.; Puech-Pagès, V.; Dun, E. A.;

7 Pillot, J. P.; Letisse, F.; Matusova, R.; Danoun, S.; Portais, J. C.; Bouwmeester, H.; Bécard, G.;

8 Beveridge, C. A.; Rameau, C.; Rochange, S. F. Nature 2008, 455, 189-194; $\quad$ (b) Leyser, O.

9 Dev. Cell 2008, 15, 337-338; (c) Shinohara, N.; Taylor, C.; Leyser, O. PLoS Biol. 2013, 11;

(d) Rameau, C.; Bertheloot, J.; Leduc, N.; Andrieu, B.; Foucher, F.; Sakr, S. Front. Plant

11 Sci. 2015, 5.

$12(3)$

(a) Koltai, H. Ann. Bot. 2013, 112, 409-415; (b) Rasmussen, A.; Depuydt, S.;

13 Goormachtig, S.; Geelen, D. Planta 2013, 238, 615-626;

(c) Koltai, H. New Phytol. 2011, 190, $14 \quad 545-549$.

(4) Urquhart, S.; Foo, E.; Reid, J. B. Physiol. Plantarum 2015, 153, 392-402.

(5) (a) Akiyama, K.; Matsuzaki, K. I.; Hayashi, H. Nature 2005, 435, 824-827;

22 Anilkumar, G.; Sethumadhavan, D. Pest Manag. Sci. 2009, 65, 478-491. 
(7) (a) Ueno, K.; Furumoto, T.; Umeda, S.; Mizutani, M.; Takikawa, H.;

2 Batchvarova, R.; Sugimoto, Y. Phytochemistry 2014, 108, 122-128;

(b) Nomura, S.;

Nakashima, H.; Mizutani, M.; Takikawa, H.; Sugimoto, Y. Plant Cell Rep. 2013, 32, 829-838.

(8) Yoneyama, K. J.Pest. Sci. 2010, 35, 348-350.

(9) (a) Pollock, C. B.; McDonough, S.; Wang, V. S.; Lee, H.; Ringer, L.; Li, X.;

Prandi, C.; Lee, R. J.; Feldman, A. S.; Koltai, H.; Kapulnik, Y.; Rodriguez, O. C.; Schlegel, R.;

Albanese, C.; Yarden, R. I. Oncotarget 2014, 5, 1683-1698; $\quad$ (b) Pollock, C. B.; Koltai, H.;

Kapulnik, Y.; Prandi, C.; Yarden, R. I. Breast Cancer Res. Tr. 2012, 134, 1041-1055.

(10) For Michael acceptors natural compounds acting as anticancer agents see Sinisi,

A.; Millán, E.; Abay, S. M.; Habluetzel, A.; Appendino, G.; Muñoz, E.; Taglialatela-Scafati, O. J. Nat. Prod. 2015, 78, 1618-1623.

(11) (a) Zwanenburg, B.; Nayak, S. K.; Charnikhova, T. V.; Bouwmeester, H. J.

Bioorg. Med. Chem. Lett. 2013, 23, 5182-5186; $\quad$ (b) Mwakaboko, A. S.; Zwanenburg, B.

Plant Cell Physiol. 2011, 52, 699-715.

(12) Ueno, K.; Sugimoto, Y.; Zwanenburg, B. Phytochem. Rev. 2014, 1-13.

(13) Xie, X.; Yoneyama, K.; Kisugi, T.; Uchida, K.; Ito, S.; Akiyama, K.; Hayashi, H.;

Yokota, T.; Nomura, T.; Yoneyama, K. Mol. Plant 2013, 6, 153-163.

(14) Hamiaux, C.; Drummond, R. S. M.; Janssen, B. J.; Ledger, S. E.; Cooney, J. M.;

Newcomb, R. D.; Snowden, K. C. Curr. Biol. 2012, 22, 2032-2036.

(15) (a) Kagiyama, M.; Hirano, Y.; Mori, T.; Kim, S. Y.; Kyozuka, J.; Seto, Y.; Yamaguchi, S.; Hakoshima, T. Genes Cells 2013, 18, 147-160; $\quad$ (b) Zhao, J.; Wang, T.;

Wang, M.; Liu, Y.; Yuan, S.; Gao, Y.; Yin, L.; Sun, W.; Peng, L.; Zhang, W.; Wan, J.; Li, X. Plant Cell Physiol. 2014, 55, 1096-1109. 
(16) Jiang, L.; Liu, X.; Xiong, G.; Liu, H.; Chen, F.; Wang, L.; Meng, X.; Liu, G.; Yu,

2 H.; Yuan, Y.; Yi, W.; Zhao, L.; Ma, H.; He, Y.; Wu, Z.; Melcher, K.; Qian, Q.; Xu, H. E.; Wang, 3 Y.; Li, J. Nature 2013, 504, 401-405.

4 (17) Chiwocha, S. D. S.; Dixon, K. W.; Flematti, G. R.; Ghisalberti, E. L.; Merritt, D.

5 J.; Nelson, D. C.; Riseborough, J. A. M.; Smith, S. M.; Stevens, J. C. Plant Sci. 2009, 177, 2526256. $11 \quad 1059-1072$.

12
(18) Scaffidi, A.; Waters, M. T.; Sun, Y. K.; Skelton, B. W.; Dixon, K. W.;

Ghisalberti, E. L.; Flematti, G. R.; Smith, S. M. Plant Physiol. 2014, 165, 1221-1232.

(19) Umehara, M.; Mengmeng, C.; Akiyama, K.; Akatsu, T.; Seto, Y.; Hanada, A.;

Weiqiang, L.; Takeda-Kamiya, N.; Morimoto, Y.; Yamaguchi, S. Plant Cell Physiol. 2015,

(20) Prandi, C.; Ghigo, G.; Occhiato, E. G.; Scarpi, D.; Begliomini, S.; Lace, B.; Alberto, G.; Artuso, E.; Blangetti, M. Org. Biomol. Chem. 2014, 12, 2960-2968.

(21) (a) Cohen, M.; Prandi, C.; Occhiato, E. G.; Tabasso, S.; Wininger, S.; Resnick, N.; Steinberger, Y.; Koltai, H.; Kapulnik, Y. Mol. Plant 2013, 6, 141-152; (b) Prandi, C.; Occhiato, E. G.; Tabasso, S.; Bonfante, P.; Novero, M.; Scarpi, D.; Bova, M. E.; Miletto, I. Eur. J. Org. Chem. 2011, 3781-3793.

(22) Prandi, C.; Rosso, H.; Lace, B.; Occhiato, E. G.; Oppedisano, A.; Tabasso, S.; Alberto, G.; Blangetti, M. Mol. Plant 2013, 6, 113-127.

(23) Bhattacharya, C.; Bonfante, P.; Deagostino, A.; Kapulnik, Y.; Larini, P.; Occhiato, E. G.; Prandi, C.; Venturello, P. Org. Biomol. Chem. 2009, 7, 3413-3420. (24) (a) Pereira, N. A. M.; Pinho e Melo, T. M. V. D. Org. Prep. Proced. Int. 2014, 46, 183-213; (b) Ni, Y.; Wu, J. Org. Biomol. Chem. 2014, 12, 3774-3791;

(c) Ptaszek, 
$1 \quad$ M.: Rational Design of Fluorophores for In Vivo Applications. In Fluorescence-Based

2 Biosensors: From Concepts to Applications; Morris, M. C., Ed.; Progress in Molecular Biology 3 and Translational Science, 2013; Vol. 113; pp 59-108.

4 (25) Reizelman, A.; Wigchert, S. C. M.; Del-Bianco, C.; Zwanenburg, B. Org.

5 Biomol. Chem. 2003, 1, 950-959.

6

(26) Kaminski, Z. J.; Paneth, P.; Rudzinski, J. J. Org. Chem. 1998, 63, 4248-4255.

(27) S. Parsons, H. D. F. a. T. W. Acta Cryst. 2013, 249-259.

(28) Crystallographic data for the structure reported in this paper have been deposited with the Cambridge Crystallographic Data Centre with the CCDC number 1403160. Copies of the data can be obtained, free of charge, on application to the Director, CCDC, 12 Union Road, Cambridge CB2 1EZ, UK (fax: +44-(0)1223-336033 or e-mail: deposit@ccdc.cam.ac.uk).

(29) Frischmuth, K.; Wagner, U.; Samson, E.; Weigelt, D.; Koll, P.; Meuer, H.; Sheldrick, W. S.; Welzel, P. Tetrahedron-Asymmetr. 1993, 4, 351-360.

(30) Nomura, S.; Nakashima, H.; Mizutani, M.; Takikawa, H.; Sugimoto, Y. Plant Cell Reports 2013, 32, 829-838.

(31) Santoro, E.; Mazzeo, G.; Petrovic, A. G.; Cimmino, A.; Koshoubu, J.; Evidente, A.; Berova, N.; Superchi, S. Phytochemistry 2015, 116, 359-366.

(32) Scaffidi, A.; Waters, M. T.; Sun, Y. K.; Skelton, B. W.; Dixon, K. W.;

Ghisalberti, E. L.; Flematti, G. R.; Smith, S. M. Plant Physiology 2014, 165, 1221-1232.

(33) Kapulnik, Y.; Delaux, P. M.; Resnick, N.; Mayzlish-Gati, E.; Wininger, S.;

Bhattacharya, C.; Séjalon-Delmas, N.; Combier, J. P.; Bécard, G.; Belausov, E.; Beeckman, T.; Dor, E.; Hershenhorn, J.; Koltai, H. Planta 2011, 233, 209-216. 
(34) Cohen, M.; Prandi, C.; Occhiato, E. G.; Tabasso, S.; Wininger, S.; Resnick, N.;

2 Steinberger, Y.; Koltai, H.; Kapulnik, Y. Mol. Plant 2013, 6, 141-152.

3

4 Reinhardt, D.; Bours, R.; Bouwmeester, H. J.; Martinoia, E. Nature 2012, 483, 341-344.

5
(35) Kretzschmar, T.; Kohlen, W.; Sasse, J.; Borghi, L.; Schlegel, M.; Bachelier, J. B.;

(36) Sasse, J.; Simon, S.; Gübeli, C.; Liu, G. W.; Cheng, X.; Friml, J.; Bouwmeester, H.; Martinoia, E.; Borghi, L. Curr. Biol. 2015, 25, 647-655.

(37) Fridlender, M. L., B.; Wininger, S,; Dam, A.; Kumari, P.; Belausov, E.;

Tsemach, H.; Kapulnik, Y.; Prandi, C.; Koltai, K. Mol. Plant 2015, in press, 10.1016/j.molp.2015.1008.1013.

(38) Umpublished data

(39) Zwanenburg, B.; Thuring, J. Pure and Applied Chemistry 1997, 69, 651-654.

(40) Sheldrick, S. M. Acta Cryst. 2015, A71, 3-8.

(41) O. V. Dolomanov, L. J. B., R. J. Gildea, J. A. K. Howard and H. Puschmann

列

6




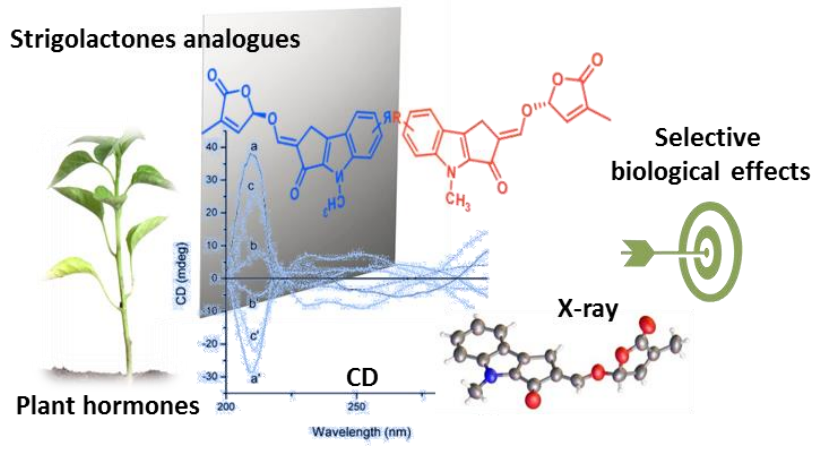

